\title{
OXYGEN ISOTOPE FRACTIONATION BETWEEN BIRD EGGSHELL CALCITE AND BODY WATER: APPLICATION TO FOSSIL EGGS FROM LANZAROTE (CANARY ISLANDS)
}

\author{
Lazzerini, N. ${ }^{\text {ab }}$, Lécuyer, C. ${ }^{a}$, Amiot, R. ${ }^{a}$, Angst, D.c, Buffetaut, E. ${ }^{d}$, Fourel, F.a, Daux, V. ${ }^{e}$,
} Betancort, J.F. ${ }^{f}$, Flandrois, J.-P. ${ }^{g}$, Marco, A.S. ${ }^{\text {h }}$, Lomoschitz, A. ${ }^{i}$

\footnotetext{
a UMR 5276, Laboratoire de Géologie de Lyon, Planètes et Environnement, Université Claude Bernard, Lyon 1/CNRS/École Normale Supérieure de Lyon, Terre, Villeurbanne Cedex, France

b Institut Universitaire de France, 103 Boulevard, Saint-Michel, Paris, France

c Paleaobiology Research Group, Biological Sciences Department, University of Cape Town, Private Bag X3, Rhodes Gift, Cape Town, South Africa

d Centre National de la Recherche Scientifique, UMR 8538, Laboratoire de Géologie de l'Ecole Normale Supérieure, Paris cedex 05, France

e Laboratoire des Sciences du Climat et de l'Environnement/IPSL, UMR CEA/CNRS 1572, L'Orme des Merisiers, Bât. 701, CEA Saclay, Gif/Yvette Cedex, France

f Departamento de Biología, Universidad de Las Palmas de Gran Canaria (ULPGC), Las Palmas de Gran Canaria, Canary Islands, Spain g CNRS, UMR5558, Laboratoire de Biométrie et Biologie Évolutive, University Lyon, Université Lyon 1, 43 bd du 11 novembre 1918, Villeurbanne, France

h Institut Català de Paleontologia Miquel Crusafont, Barcelona, Spain

i Instituto de Oceanografía y Cambio Global, Universidad de Las Palmas de Gran Canaria, Las Palmas de Gran Canaria, Canary Islands, Spain
}

\section{ABSTRACT}

Oxygen and carbon isotope compositions of fossil bird eggshell calcite $\left(\delta^{18} \mathrm{O}_{\text {calc }}\right.$ and $\delta^{13} \mathrm{C}_{\text {calc }}$ ) are regularly used to reconstruct paleoenvironmental conditions. However, the interpretation of $\delta^{18} \mathrm{O}_{\text {calc }}$ values of fossil eggshells has been limited to qualitative variations in local climatic conditions as oxygen isotope fractionations between calcite, body fluids, and drinking water have not been determined yet. For this purpose, eggshell, albumen water, and drinking water of extant birds have been analyzed for their oxygen and carbon isotope compositions. Relative enrichments in ${ }^{18} \mathrm{O}$ relative to 160 between body fluids and drinking water of $+1.6 \pm 0.9 \%$ o for semi-aquatic birds and of $+4.4 \pm 1.9 \%$ ofor terrestrial birds are observed. Surprisingly, no significant dependence to body temperature on the oxygen isotope fractionation between eggshell calcite and body fluids is observed, suggesting that bird eggshells precipitate out of equilibrium. Two empirical equations relating the $\delta^{18} \mathrm{O}_{\text {calc }}$ value of eggshell calcite to the $\delta^{18} \mathrm{OW}$ value of ingested water have been established for terrestrial and semi-aquatic birds. These equations have been applied to fossil eggshells from Lanzarote in order to infer the ecologies of the Pleistocene marine bird Puffinus sp. and of the enigmatic giant birds 
from the Pliocene. Both $\delta^{13} \mathrm{C}_{\text {calc }}$ and $\delta^{18} \mathrm{O}_{\text {calc }}$ values of Puffinus eggshells point to a semiaquatic marine bird ingesting mostly seawater, whereas low $\delta^{13} C_{\text {calc }}$ and high $\delta^{18} \mathrm{O}_{\text {calc }}$ values of eggshells from the Pliocene giant bird suggest a terrestrial lifestyle. This set of equations can help to quantitatively estimate the origin of waters ingested by extinct birds as well as to infer either local environmental or climatic conditions. 